\title{
Tuneable ionic control of polymeric films for inkjet based 3D printing
}

\author{
Erno Karjalainen, ${ }^{1}$ Dominic J. Wales, ${ }^{1}$ Deshani H.A.T. Gunasekera, ${ }^{1}$ Jairton Dupont, ${ }^{2,3}$ Peter Licence, ${ }^{2}$ \\ Ricky D. Wildman, ${ }^{1}$ Victor Sans ${ }^{1,2 *}$
}

\author{
${ }^{1}$ Faculty of Engineering, University of Nottingham, University Park, NG7 2RD, Nottingham, UK \\ ${ }^{2}$ GSK Carbon Neutral Laboratory, University of Nottingham, Nottingham, NG8 2GA, UK \\ ${ }^{3}$ Institute of Chemistry, Universidade Federal do Rio Grande do Sul, Av. Bento Gonçalves, 9500 Porto Alegre, Brazil \\ e-mail: victor.sanssangorrin@nottingham.ac.uk
}

Keywords: polymeric ionic liquids, inkjet, 3D printing, smart materials, additive manufacturing, mechanical properties

\begin{abstract}
Inkjet printing is a powerful additive manufacturing (AM) technique to generate advanced and complex geometries. However, requirements of low viscosity and surface tension are limiting the range of functional inks available, thus hindering the development of novel applications and devices. Here, we report a method to synthesise materials derived from highly viscous or even solid monomers in a simple, flexible fashion and with the potential to be integrated in the printing process. Polymerizable ionic liquids (PILs) have been employed as a proof of principle due to the broad range of properties available upon fine tuning of the anion/cation pair and the high viscosity of the monomers. The method consists of the deposition and polymerization of a PIL precursor, followed sequentially by quaternization and anion metathesis of the films. The fine control over the mechanical and superficial properties of inkjet printable polymeric films of neutral and cationic nature by post-polymerization reactions is demonstrated for the first time. A family of different polycationic materials has been generated by modification of cross-linked copolymers of butyl acrylate and vinyl imidazole with liquid solutions of functional reagents. The variation in the mechanical, thermal and surface properties of the films demonstrates the success of this approach. The same concept has been applied to a modified formulation, designed for optimal inkjet printing. This work will pave the way for a broad range of applications of inkjet printing, with a plethora of anion-cation combinations characteristic of PILs, thus enormously broadening the range of applications available in additive manufacturing.
\end{abstract}

\begin{abstract}
Introduction
Inkjet printing has gained a great deal of attention in the recent years as an Additive Manufacturing (AM) technique, ${ }^{1}$ with a range of applications developed in tissue engineering, ${ }^{2}$ flexible electronics, ${ }^{3-4}$ supercapacitors,${ }^{5}$ sensors, ${ }^{6}$ solar cells ${ }^{7}$ and many others. In addition, it has been estimated by Visser et al. that the intensities of energy usage and $\mathrm{CO}_{2}$ emissions from manufacturing are reducible by $5 \%$ through the use of 3D printing (additive manufacturing) by 2025 , and if $3 \mathrm{D}$ printing was utilised more widely, it has the potential to fully decouple energy usage and $\mathrm{CO}_{2}$ emission from manufacturing activities. ${ }^{8}$
\end{abstract}

Nevertheless, the technique requires low viscosity (typically $10-20 \mathrm{mPa} \mathrm{s}$ ) and surface tension in the order of $28-42 \mathrm{mNm}^{-1}$ in order to satisfactorily generate the droplets to be printed. ${ }^{1}$ These features strongly limit the nature and type of inks that can be employed, hence limiting the number of active materials that can be printed. In this way, the preparation of viable formulations is arduous and inefficient.

Polyionic polymers with analogous units to ionic liquids ${ }^{9}$ constitute a very interesting class of materials due to the inherent modularity of their properties by the choice of cation and anion, which in synergy with the physical properties of the polymer have a profound effect on the macroscopic properties observed. ${ }^{10-12}$ The large amount of potential anion-cation combinations leads to a virtually unlimited library of ionic materials with potential applications in a broad range of fields, including as polyelectrolytes for dye sensitized solar cells, ${ }^{13}$ membranes for fuel cells, ${ }^{14}$ super capacitors, ${ }^{15}$ support for catalysts ${ }^{16}$ and antimicrobials. ${ }^{17}$ Furthermore, their highly tuneable intermolecular forces make them ideal materials to stabilize nanoparticles $^{18}$ and other advanced materials, like carbon nanotubes ${ }^{19}$ or graphene ${ }^{20}$ and graphene oxide. ${ }^{21}$ The properties of polycations are radically affected by the choice of counterion. ${ }^{22}$ In addition to solubility, also other properties such as thermal decomposition temperature and glass transition temperature $(\mathrm{Tg})$ can be tuned with anion exchange. ${ }^{23}$ It has been demonstrated that some properties of bulk ionic liquids are effectively transferred to the polymeric supported phases. ${ }^{24}$ Generally, they are synthesised from monomers containing ionic liquid units by different polymerization techniques. These monomers are generally too viscous to be processed by inkjet printing. An example of 3D printing PILs employing micro-stereolithography has been reported. ${ }^{25}$ However, this technique requires relatively viscous formulations to be successfully printed, which is incompatible with inkjet printing. Herein, we propose a method to generate 
PIL containing films based on low viscosity inks that can be incorporated into inkjet printers. The deposition of a PIL precursor, followed by the quaternization and anion metathesis represents a novel way to generate virtually any PIL desired and will be highly useful in additive manufacturing (Figure 1). Polymeric films have been photopolymerized and employed as

PIL precursor printing

Quaternisation
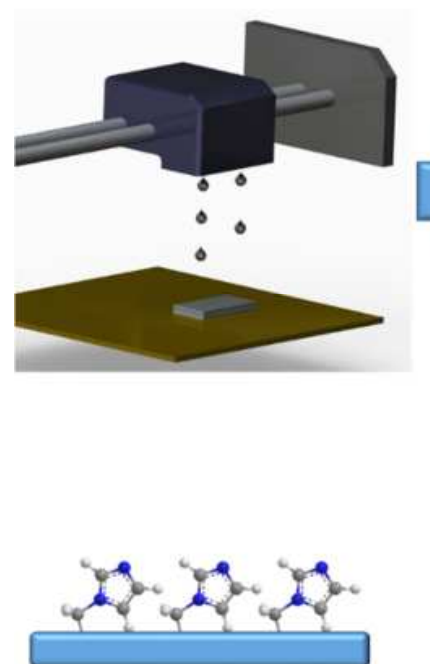
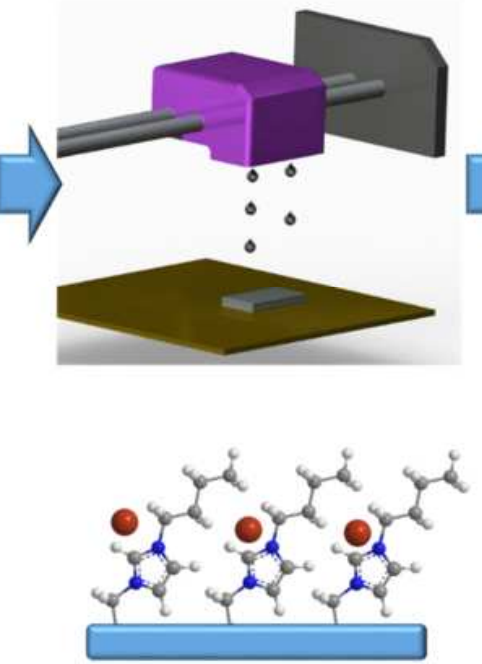

models of the inkjet printed layers. A family of imidazolium based PIL films has been synthesised and characterised.

Figure 1. Schematic representation of the method proposed to inkjet print polyionic films (PILs). The aim is to overcome the high viscosity of the monomers, enabling an integrated route to modify the properties of the printed layers.

A strong variation of the mechanical and hydrophilic/hydrophobic properties has been demonstrated. The methodology allows the manufacture of very different materials from the same original composition. The properties of the product can be then tuned by the choice of anion after the final shape has been achieved. The method removes the need of optimizing the conditions for each type of material independently. The possibility of modifying inkjet 3D printed films has been demonstrated. To the best of our knowledge, this is the first study of the properties of UV photopolymerized films modified by protonation/quaternization and anion metathesis, which is especially relevant within the context of additive manufacturing.

\section{Results and discussion}

\section{Base line formulation}

Films made of 1-vinylimidazole (ViIm) and butyl acrylate (BuA) were made with UV-polymerization using 2-hydroxy-2methylpropiophenone (HMP) as the initiator (Figure 1A). The films were crosslinked with divinyl benzene (DVB). The rationale of choosing ViIm is that it has a nitrogen atom at positon 3 of the imidazole ring that can be easily derivatised. The glass transition temperature $\left(\mathrm{T}_{\mathrm{g}}\right)$ of poly(vinyl imidazole) (PViIm) has been reported to be in range of $167-171{ }^{\circ} \mathrm{C} .{ }^{26}$ In order to make the films more flexible, butyl acrylate was used as a comonomer; $\mathrm{T}_{\mathrm{g}}$ of poly(butyl acrylate) is $-43{ }^{\circ} \mathrm{C} .{ }^{27}$ The synthesis of the films, schematically shown in Figure 1A, was made by polymerization of the films onto Teflon covered petri dishes and photopolymerized under a UV-light (36 $\mathrm{W}$ and $\lambda=395$ $\mathrm{nm})$.

Two series of films were synthesized: one with $2 \mathrm{~mol} \%$ of DVB in the feed (film 2-x series) and another one with $5 \mathrm{~mol} \%$ of DVB (film 5-x series) for comparison. The butyl acrylate content was varied between 0 and $50 \mathrm{~mol} \%$ within both series. The films have been named as "film a-x", where "a" is the DVB content in feed (either " 2 " for $2 \mathrm{~mol} \%$ DVB or " 5 " for $5 \mathrm{~mol} \%$ DVB) and " $x$ " is the butyl acrylate content in the feed. As an example, films of 2-50 were made using $2 \mathrm{~mol} \%$ of DVB and $50 \mathrm{~mol} \%$ of BuA. Only monomers are considered for the percentages. All the films were made using $2 \mathrm{~mol} \%$ of the photoinitiator HMP compared to the total amount of all monomers and with polymerization time of $2 \mathrm{~h}$ exposed to UV-light ( $36 \mathrm{~W}$ and $365 \mathrm{~nm}$ ). The exact amounts of all components used to make the films are given in Table $\mathbf{S 1}$ in the supporting information (SI). The purity of the films was verified from IR spectra. The strong bands corresponding to the double bonds at 1620-1650 $\mathrm{cm}^{-1}$ and at $950-990 \mathrm{~cm}^{-1}$ in the IR spectra of the monomers (Figure S1) could not be observed in the films (Figures S2 and S3), which indicates that the films are mostly free of monomers.

The films became more flexible with increasing butyl acrylate content. This is especially marked in the film 2-x series as the initially hard and brittle films became soft and elastic as the butyl acrylate content was increased from 0 to $50 \%$ (Figure 2A). The strain at break increased from $0.42 \%$ to $100 \%$ (Figure 2D). Analogous results were obtained with the film 5-x series (Figure S4), the only difference being that the higher degree of crosslinking resulted in generally lower strains at break, but stiffer films. Also in this case the increasing butyl acrylate content yielded markedly more flexible films. Highly brittle Film 5-0 was crushed by the clamping of the DMA, but film 5-50 with $50 \mathrm{~mol} \%$ of butyl acrylate in the feed could be strained $25 \%$ before the film broke. Figure 2D summarizes the strain at break and stress at break for 2-x films. The measurement temperature was $25^{\circ} \mathrm{C}$. The higher butyl acrylate contents yielded more flexible films that required less stress to break. However, as the content of butyl acrylate decreases below $30 \mathrm{~mol} \%$, the films became brittle as both strain at break and stress at break started to decrease (Figure 2D). ${ }^{28}$ This increase in brittleness is due the glass transition $\left(\mathrm{T}_{\mathrm{g}}\right)$ temperature - seen as a peak in in the loss tangent $(\tan \delta)$ - being well above $25^{\circ} \mathrm{C}$ when the butyl acrylate content is $20 \mathrm{~mol} \%$ or less (Figure 2C) and thus the 
films become glassy and brittle. The storage (E') and loss moduli (E') as a function of temperature that were used to calculate the values of $\tan \delta$ in Figure 2 are shown in Figure S5. A similar trend was observed when the amount of cross-linker (DVB) was increased to $5 \mathrm{~mol} \%$ (see Figures S6 and S7).
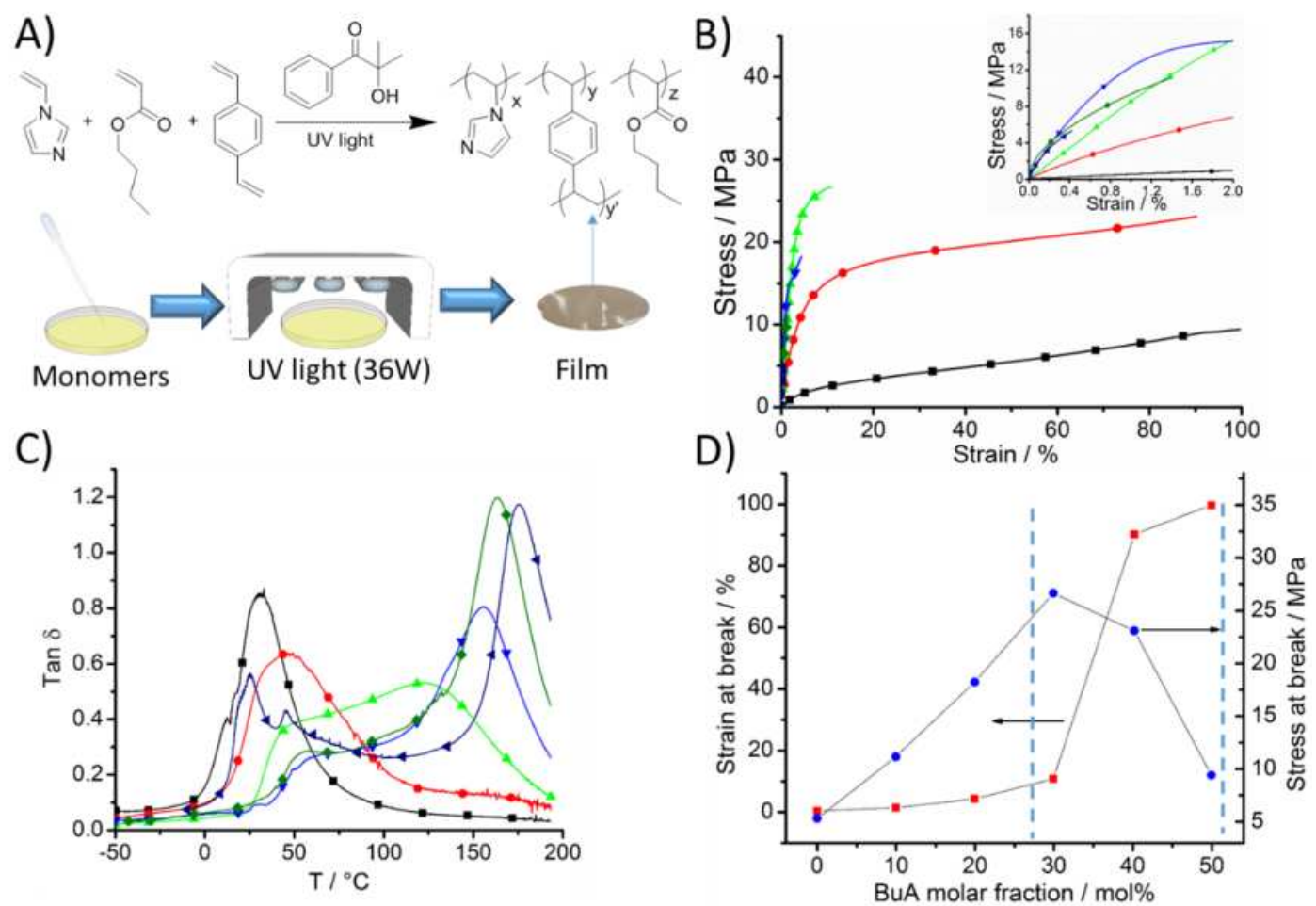

Figure 2 (A) Scheme of the monomers and initiator employed for the film formation and schematic representation of the methodol-

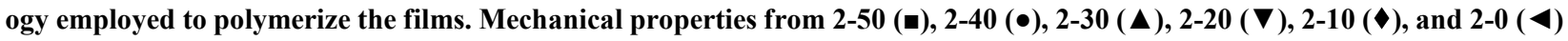
films represented by (B) stress-strain curves, including a close up image from the low strain area and (C) the tan $\delta$ as a function of temperature. Only 1 point in 100 is shown for clarity. (D) Stress and strain at break as a function of the molar fraction of butyl acrylate.

There is a transition seen as a shoulder in $\tan \delta$ between 25 $60{ }^{\circ} \mathrm{C}$ in most $\tan \delta$ measurements (Figure 2C). A secondary transition has been reported in literature for polymers containing quaternized imidazolium rings. ${ }^{29-30}$ The transition was found to arise from ionic interactions and local motions. This particular case is slightly different since the imidazole rings are in their neutral state, so it is not certain if the phenomena are related. This effect could be ascribed to pi-pi interactions of the imidazole rings. ${ }^{31}$ As the transition can be seen also in film 2-0, it can be rationalized to arise from interactions between the imidazolium rings for ViIm or the phenyl rings from DVB and not from e.g. phase separation of a BuA rich phase in the film. The exact nature of the shoulder would be a subject of a study of its own and therefore outside the scope of this article.

The thermal stability of the films decreased with increasing BuA content (Figures S8 and Figures S9). The mechanical properties of the films are summarized in Table S2. Young's modulus (E) was defined as a slope of a linear fit to the linear part of the stress-strain curves, see Figure S10 for an example.

Post-polymerization tuning of film properties

Three most flexible films i.e. films 2-30, 2-40, and 2-50, were chosen to be studied for the post polymerization modification utilizing the nitrogen at position 3 of the imidazolium ring. The films were first modified in a non-covalent manner by first protonating the film with $\mathrm{HCl}$ (film 2-x $\mathrm{HCl}$ ) and then exchanging the anion with bis(trifluoromethane)sulfonimide $\left(\mathrm{NTf}_{2}\right)($ film 2$\mathrm{x} \mathrm{HNTf}_{2}$ ). Also, protonation with dodecanoic acid (film 2-x HDA) was investigated. In addition to protonation, films were also covalently modified by quaternization with 1-bromobutane (film 2-x $\mathrm{C}_{4} \mathrm{Br}$ ), which yields ionic films that have a more permanent charge. These films were also anion exchanged with $\mathrm{LiNTf}_{2}$ (film 2-x C $\mathrm{NTf}_{2}$ ). The modification of the films is illustrated in Scheme 1. In this way, five more films could be synthesized from each parent film.

The different methods of derivatization shown in Scheme 1 have been selected as a proof of concept to demonstrate the dramatic effect on the mechanical, thermal and superficial properties of the resulting polymeric films. The glass transition temperature $\left(\mathrm{T}_{\mathrm{g}}\right)$ of polymeric films is heavily influenced by introducing charged groups. ${ }^{32-33}$ Indeed, an increase of $114{ }^{\circ} \mathrm{C}$ for protonation (film 2-40 $\mathrm{HCl}$ ) and $89.3{ }^{\circ} \mathrm{C}$ for quaternization (film 2-40 $\mathrm{C}_{4} \mathrm{Br}$ ) were observed (Figure 3). The metathesis of the anion led to a $\mathrm{T}_{\mathrm{g}}$ decrease of $116.6^{\circ} \mathrm{C}$ (film 2-40 $\mathrm{NTf}_{2}$ ) and $112.6{ }^{\circ} \mathrm{C}$ (film 2-40 $\mathrm{C}_{4} \mathrm{NTf}_{2}$ ). The aim of using dodecanoic acid was to lower the $\mathrm{T}_{\mathrm{g}}$ in one non-covalent step. It has been shown 
that a long chain aliphatic carboxylate anion can be used to yield rubbery polyelectrolytes. ${ }^{34}$

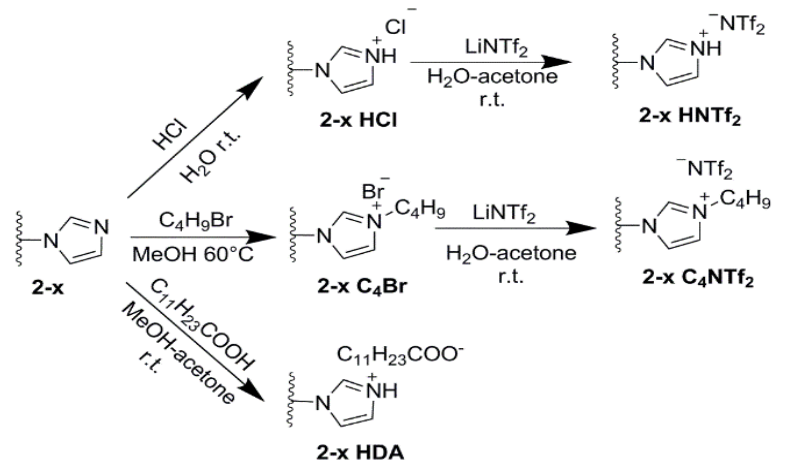

Scheme 1. Derivatization of the films. Illustrated for one imidazole ring in the films.

The changes in glass transition temperatures are reflected also in the stress-strain curves of the modified films (Figure 3B). A representative set of mechanical and thermal properties is shown in Table 1. The rest of the series studied followed similar trends. The $\mathrm{C}_{4} \mathrm{NTF}_{2}$ films, had the lowest glass transition temperatures (Figure 3A) and required also least force to strain i.e. had the lowest Young's modulus of the series. They also had the highest strains at break within each series. Their halide counterparts, the $\mathrm{C}_{4} \mathrm{Br}$ films, were the most brittle films, which reflects the enormous effect of the counter-ion to the thermomechanical properties of polyelectrolytes. The protonation of the film with $\mathrm{HCl}$ showed a similar effect. Although the $\mathrm{HCl}$ films were much more flexible than the $\mathrm{C}_{4} \mathrm{Br}$ films, they were still very brittle. The ion exchange with $\mathrm{NTf}_{2}$ did make the films again much more flexible, but to a lesser extent than was the case with the $\mathrm{C}_{4} \mathrm{Br}$ series. Curiously, the $\mathrm{HNTf}_{2}$ films were stiffer than the original films in the cases of film 2-40 $\mathrm{HNTf}_{2}$ (Figure 3B) and film 2-50 $\mathrm{HNTf}_{2}($ Figure S11B), whereas in the case of film 2-30 $\mathrm{HNTf}_{2}$ (Figure S11A) the Young's modulus was somewhat lower. This reflects similar trends than were observed with the glass transition temperatures as film 2-30 $\mathrm{HNTf}_{2}$ was the only one with a significantly lower value of $\mathrm{T}_{\mathrm{g}}$ than the original film. The strains at break stay significantly below the ones for the original films in all three cases.

Table 1. Mechanical and thermal properties of functionalised films

\begin{tabular}{llllll}
\hline Film & $\mathrm{T}_{\mathrm{g}}\left({ }^{\circ} \mathrm{C}\right)$ & $\begin{array}{l}\text { Strain } \\
\text { at } \\
\text { break } \\
/ \%\end{array}$ & $\begin{array}{l}\text { Stress at } \\
\text { break } \\
\mathrm{MPa}\end{array}$ & $\begin{array}{l}\mathrm{T}_{\text {onset }} / \\
{ }^{\circ} \mathrm{C}\end{array}$ & $\begin{array}{l}\Delta \mathrm{T}_{\text {onset }} / \\
{ }^{\circ} \mathrm{C}^{\mathrm{a})}\end{array}$ \\
\hline $2-40$ & 49.3 & 90.2 & 23.1 & 242 & 0 \\
$2-40$ & 163.6 & 2.7 & 28.8 & & \\
$\mathrm{HCl}$ & & & & 201 & -41 \\
$2-40$ & 46.9 & 5.2 & 27.8 & & \\
$\mathrm{NTf} 2$ & & & & 301 & 59 \\
$2-40$ & 33.4 & 45.4 & 24.5 & & \\
$\mathrm{HDA}$ & & & & 235 & -7 \\
$2-40$ & 138.6 & 0.6 & 6.6 & & \\
$\mathrm{C} 4 \mathrm{Br}$ & & & & 214 & -28 \\
$2-40$ & 26.0 & 94.9 & 9.8 & & \\
$\mathrm{NTf} 2$ & & & & 284 & 42 \\
\hline
\end{tabular}

a) Calculated as the difference between $T_{\text {onset }}$ of the film minus that of the original film 2-40
Both the quaternized and protonated films display clearly the effect of the large $\mathrm{NTf}_{2}$ anion with a delocalized charge compared to a halide anion on both mechanical properties equally in variable temperature measurements (Figures S12-S14) and at room temperature (Figure 3A). These results also prove the high versatility of the approach chosen for the films.

Perhaps surprisingly, addition of dodecanoic acid made the films tough (HDA series in Figure 3B) i.e. the films had both high Young's moduli and high strain at break, which are ideal mechanical properties for photopolymerized materials. ${ }^{35}$

The derivatization of the films produce a strong effect on the thermal decomposition behavior of the different films. The immediate effect of both the protonation and quaternization of the film is that the thermal stability decreases, but the ion exchange with $\mathrm{NTf}_{2}$ makes both the protonated and quaternaised film more thermally stable than the original one. The derivatives of film 2-30 and 2-40 are identical to derivatives of film 2-50 in terms of thermal stabilities (Figure S18-S19). This is consistent with literature reports in different types of polyionic materials. ${ }^{24,33}$

The decrease of thermal stability of a polybase after protonation with a hydrogen halide has been reported by other investigators as well, ${ }^{24,33}$ thus indicating the viability of this strategy to generate functionalised films with tuneable properties. Furthermore, the thermal stabilities of the model compounds (Figure S23) follow similar trends than do the films with one exception: the thermal stability of PViIm HDA is markedly lower than that of HDA derivatives of any of the films. This may be a consequence of incomplete derivatization as discussed above or it could arise from differences between soluble polymers and crosslinked films.
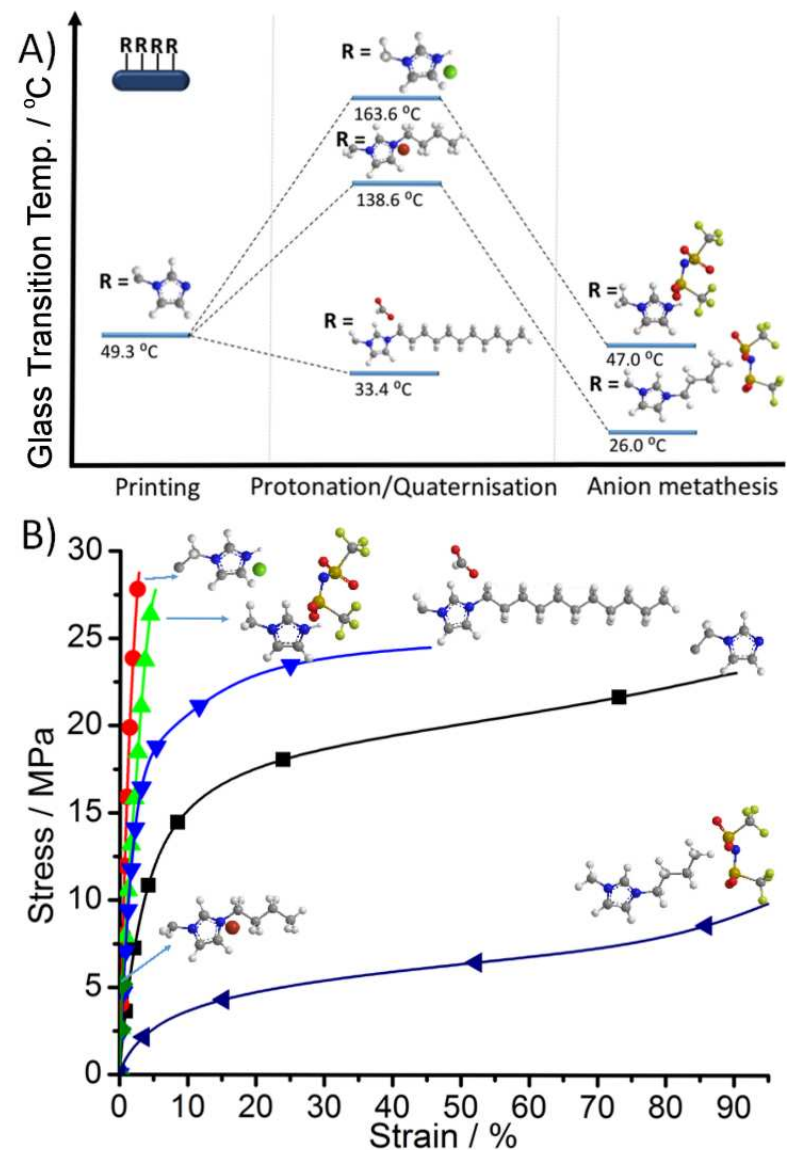
Figure 3 A) Experimental glass transition temperature, $T_{g}$, of the film 2-40 and the post-modified series. The glass transition temperature is defined as the temperature corresponding to a maximum of $\tan \delta$. B) Stress-strain curves for the modified films for the 2-40 series. Only 1 point in 100 shown for clarity.

A higher content of ViIm in the film yields a wider range of glass transition temperatures (Figure 4 and S20). This indicates that the changes arise from the modification of these particular groups. Derivatives film 2-30 have the widest range glass transition temperatures ranging from $32{ }^{\circ} \mathrm{C}$ of film 2-30 $\mathrm{C}_{4} \mathrm{NTf}_{2}$ to $176^{\circ} \mathrm{C}$ of film 2-30 HCl. Although it was unclear from both IR (Figure S21) and TGA (Figures S18-S19) whether or not dodecanoic acid is incorporated to the films or not, the lowering of $T_{g}$ in all cases below the value of the original film strongly suggests that dodecanoic acid has been incorporated at least to some extent. Thus, it allows a convenient way to lower the $T_{g}$ of films of this type in one simple step.

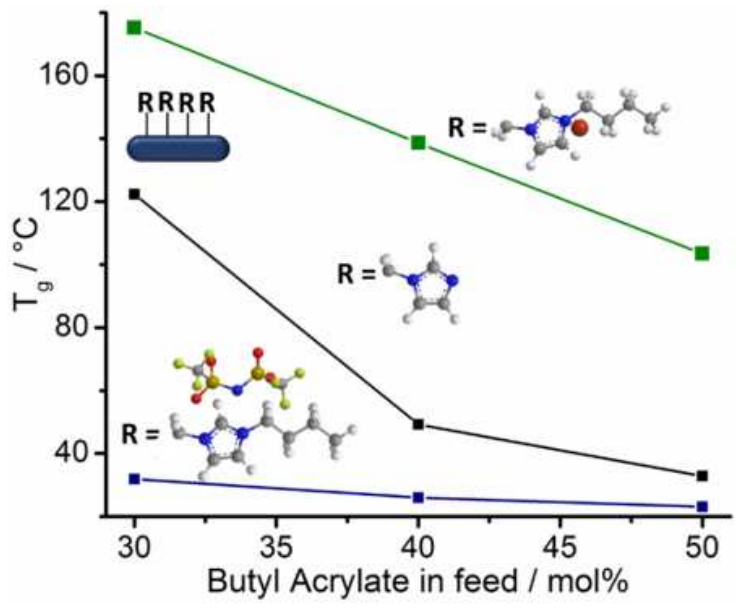

Figure 4. Effect of butyl acrylate on the $\mathrm{Tg}$ as a function of the imidazole group functionalisation.

A series of model compounds were synthesized from poly(vinyl imidazole) (PViIm ) by similar protonation and ion exchange strategy to generate analogous species to the different films. This was done to validate the analytical observations for the different films by comparison to polymers with well-defined composition. The homopolymers were characterised by NMR, IR, DSC and TGA. The results indicate that all the transformations were successful, which is a good benchmark for the supported films.

The model compounds display clear differences in their NMR (Figure S24-S29) and IR spectra compared to PViIm (Figure S30). It is worth mentioning that attempts to purify PViIm HDA by precipitation resulted in the loss of most of the dodecanoic acid, as did drying it at elevated temperatures. This is because the conjugate acid of vinyl imidazole has $\mathrm{pK}_{\mathrm{a}}$ of around 6.0 and thus unable to form stable salts. The significant decrease in thermal stability caused by introduction of HDA indicates more complex interactions beyond simple plasticization. Although the degree of protonation in the model compound in Figure S25 cannot be directly observed from the NMR-spectrum, the clear downfield shift of peak "a" indicates significant degree of protonation. This is supported by the change in thermal stability observed in Figure 23, which is in line with the literature. ${ }^{32}$

The superficial properties of a material in terms of hydrophilicity/hydrophobicity are controlled by the physico-chemical properties of the materials. Hence, a significant variation in behaviour with the functionalisation of the films would be expected. Indeed, Figure 5 shows the contact angle of deionised water in contact with the different films from the series 2-30. The initial film, containing neutral imidazolium shows a contact angle of $83.7^{\circ}$ (Figure 5A). The quaternization (Figure 5B) and protonation of the films led to highly hydrophilic surfaces. In the case of protonation (Figure 5E), the surface became so hydrophilic that the droplet just spread, thus being unable to measure a contact angle $\left(\theta<5^{\circ}\right)$. The quaternized film (Figure 5B) showed a very interesting phenomenon, where the presumably hydration of the film results in the differential expansion of the upper layers of the film, resulting in the bending of the films (see SI for a demonstrative video). The protonation with HDA and the anion metathesis of protonated and quaternized films with $\mathrm{NTf}_{2}$ (Figure 5C) resulted in an increase of the hydrophobicity. This is in line with the formation of contact ion pairs imidazolium cation-anions observed for the monomeric analogues for which the increase in the contact on pair strength reduce the ionic character of the material. ${ }^{36}$
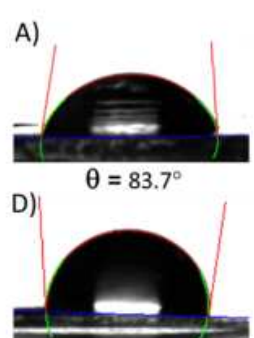

$\theta=93.9^{\circ}$
B)

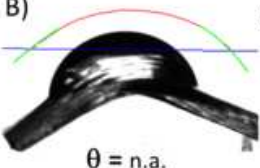

E)

E)

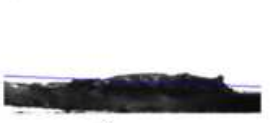

$\theta=$ n.a. $\theta=95.9^{\circ}$

$\mathrm{F}$

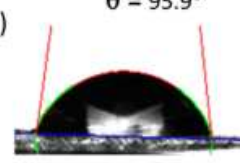

$\theta=83.7^{\circ}$

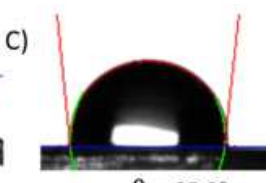

Figure 5. Effect of surface modification by quaternization and anion metathesis on the contact angle of water with the surface of the films: A) 2-30, B) $2-30 \mathrm{C}_{4} \mathrm{Br}$, C) 2-30, $\mathrm{C}_{4} \mathrm{NTf}_{2}$ D) 2-30 HDA, E) 2-30 HCl, F) 2-30 HNTf.

\section{Inkjet $3 D$ printing and functionalisation of PILs}

Finally, the possibility of functionalising $3 \mathrm{D}$ printed films to produce tuneable PIL-type materials was demonstrated. To achieve this a DIMATIX DMP-2830 was employed (Figure 6). A drop on demand (DOD) system employing piezoelectric actuators was employed to jet droplets of the formulations on an untreated glass slide. A UV LED $\left(365 \mathrm{~nm}, 600 \mathrm{~mW} / \mathrm{cm}^{2}\right)$ on the side of the ink cartridge was employed to photopolymerize the droplets during printing. Initially, a formulation similar to the one developed for the film experiments was employed (see SI for details). The mixture was able to be pushed through the nozzle and deposited on the glass surface (see SI, Video S2).

The attempts to print the original formulations formulation were unsuccessful due to the appearance of surface defects after the deposition of $c a$. 10 layers (Figure S33). This was attributed to the slow rate of polymerization inherent to 1-vinylimidazole, which prevented the solidification of the layers, thus leading to macroscopic defects after deposition of few layers of material. Another potential explanation is the insolubility of poly(vinyl imidazole) in its own monomer, which could create phase separations, leading to macroscopic defects.

Therefore, a modified formulation was developed to increase polymerization kinetics, thus allowing to print smooth layers (Scheme S1). The PIL precursor selected was 1-(4-vinylbenzyl)- $1 H$-imidazole (ViBzIm), divinyl benzene (DVB) was employed as cross-linker and diphenyl(2,4,6-trimethylben- 
zoyl)phosphine oxide (DPPO) as photoinitiator. The formulation also contained butyl acrylate (BuA), ethyl 4-(dimethylamino)benzoate (EDB) and an organic dye, 2,4-diethyl-9H-thioxanthen-9-one (DTX). The viscosity of the solution was $\sim 7-8$ $\mathrm{mPa}$ s. An addition of $6 \mathrm{wt} \%$ of PVP $\left(\mathrm{M}_{\mathrm{w}}=10000 \mathrm{Da}\right)$ raised it to $\sim 12-13 \mathrm{mPa}$, within the optimal range for printing - PVP is commonly used to tailor the viscosity of inks. ${ }^{37}$ This new formulation created very smooth and uniform printed layers in a controlled and reproducible fashion (Figure 6B).

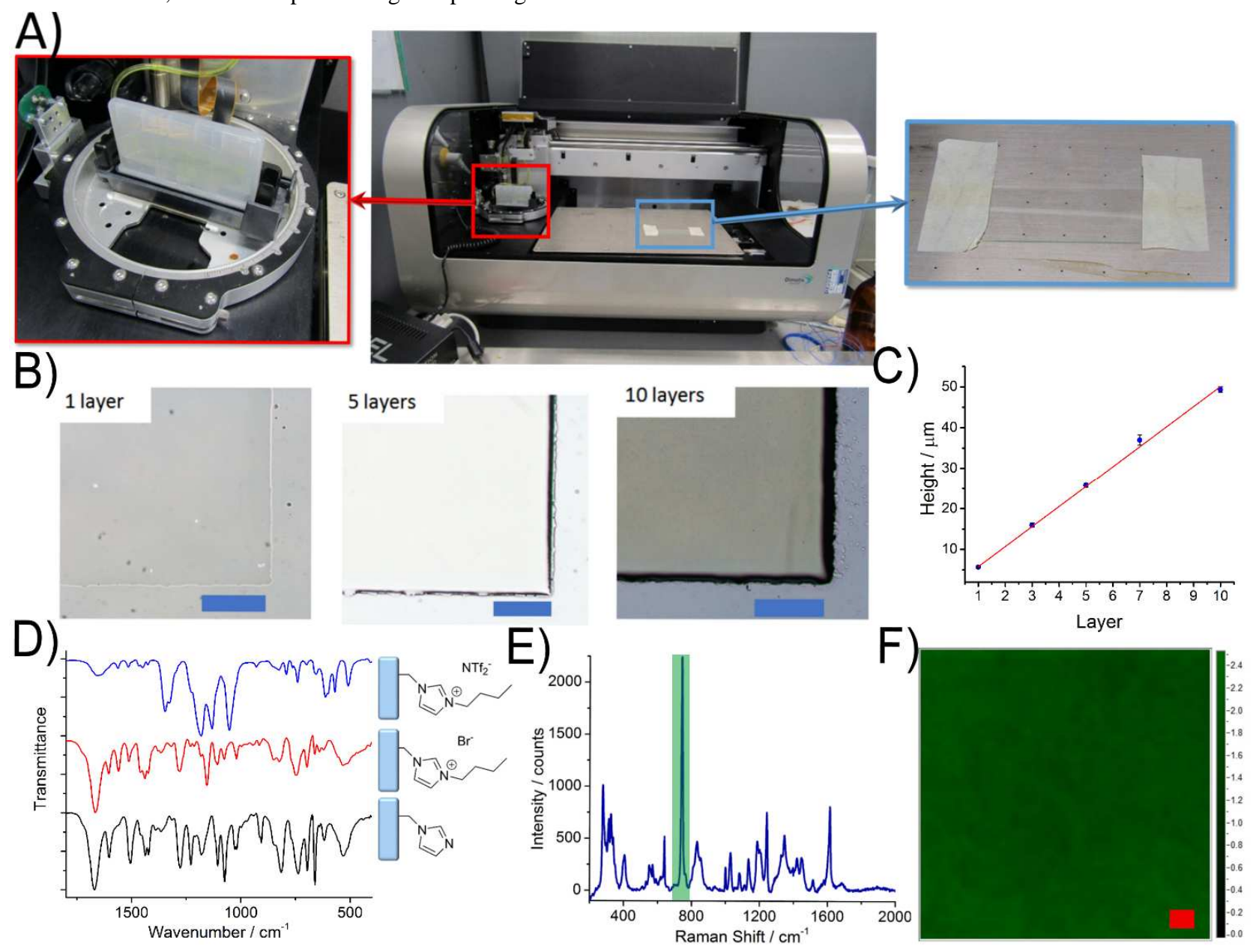

Figure 6. A) Inkjet printer employed in this work: aDimatix DMP-2830 from Fujifilm. Left: Detail of the ink cartridge support platform and the UV light associated. Centre: Picture of the inkjet printer and Right: Glass slide employed as base material for film printing. B) Optical images corresponding to the deposition and photopolymerization of different layers of PIL precursor polymer. Blue bars correspond to a scale of $500 \mu \mathrm{m}$. C) Linear fit: $y=4.84 x+0.44 R^{2}=0.999$. D) ATR-IR spectra of the original deposited film (black), quaternized with 1-bromobutane (red) and after anion metathesis with $\mathbf{N T f}_{2}$ (blue), demonstrating the ability of post-modification of inkjet 3D printed films. E) Raman spectra of the surface of the film. The band highlighted in green corresponds to the vc-s in the -NTf 2 employed for the raman microscopy mapping analysis. F) Confocal Raman microscopy xy-map (red bar corresponds to $20 \mu \mathrm{m}$ ) of the surface of an inkjet printed sample after both quaternization with 1-bromobutane and anion metathesis with $-\mathrm{NTf}_{2}$. The green highlight represents the spatial location of the $-\mathrm{NTf}_{2}$ anion in the $\mathrm{xy}$-map and was determined by normalising the intensity of the $745 \mathrm{~cm}^{-1}$ peak ( $v_{c-s}$ in the ${ }^{-N T f_{2}}$ anion) normalised to the peak in the range $1570-1650 \mathrm{~cm}^{-1} \mathrm{corre}^{-}$ sponding to the polymer.

The deposition of the layers could be finely controlled to $c a .5$ $\mu \mathrm{m}$ per layer deposited (Figure 6C). The imidazolium groups of a film made of 3 layers ( $c a .15 \mu \mathrm{m}$ thickness) was quaternized by treatment with 1-bromobutane. The ATR-IR spectra shows clearly the presence of new bands at $1160 \mathrm{~cm}^{-1}$, associated to the $\mathrm{C} 2$ in the aromatic ring of quaternary imidazolium species. ${ }^{38}$ Furthermore, the anion metathesis with $\operatorname{LiNTf}_{2}$ could be clearly observed by ATR-IR (Figure 6D and S22 for comparison) and by Raman spectroscopy (Figure 6E).
Further evidence of homogenous functionalisation of the inkjet printed sample was afforded by confocal Raman microscopy. Initially a xy-map $(230 \mu \mathrm{m} \times 230 \mu \mathrm{m})$ of the surface of an inkjet printed sample, after both quaternization with 1-bromobutane and anion metathesis with ${ }^{-} \mathrm{NTf}_{2}$, was collected and demonstrated the homogeneous distribution of the ${ }^{-} \mathrm{NTf}_{2}$ anion across the surface of the sample (Figure $\mathbf{6 F}$ ). The green coloration in Figure $6 \mathbf{F}$ represents the intensity of the peak (as area, baselined) in the range $710-780 \mathrm{~cm}^{-1}\left(v_{\mathrm{C}-\mathrm{S}}\right.$ in the ${ }^{-} \mathrm{NTf}_{2}$ anion) nor- 
malised to a peak in the range $1570-1650 \mathrm{~cm}^{-1}\left(v_{\mathrm{C}=\mathrm{N}}\right.$ in the imidazolium polymer) at each $\sim 5 \mu \mathrm{m} \times 5 \mu \mathrm{m}$ point across the surface of the sample. The uniform green coloration across the whole xy-map demonstrates uniform and homogeneous location of the ${ }^{-} \mathrm{NTf}_{2}$ anion across the surface of the sample and thus clearly demonstrates successful homogeneous functionalisation of the PIL precursor polymer by quaternization and subsequent anion metathesis. A Raman confocal microscopy z-axis (depth) spectral study was also performed (Figure S34) on a 10 layer ( $\sim 0 \mu \mathrm{m}$ thick) sample, after quaternization and anion metathesis. The presence of peak features corresponding to the $v_{\mathrm{C}-\mathrm{S}} \mathrm{By}$ normalising the peak intensity of the $v_{\mathrm{C}-\mathrm{s}}$ Raman shift at different depths to the corresponding peak intensity of the $v_{\mathrm{C}=\mathrm{N}}$ peak intensity a linear decrease in the intensity of the $v_{\mathrm{C}-\mathrm{S}}$ Raman shift peak with increasing depth was revealed (Figure S35). The raman shift in the ${ }^{-} \mathrm{NTf}_{2}$ anion $\left(\sim 745 \mathrm{~cm}^{-1}\right)$ was observed down to $25 \mu \mathrm{m}$, which confirms successful quaternization and anion metathesis of the PIL precursor polymer down to a depth that corresponds to the thickness of $c a$. 4-5 printed layers, even though it is hard to determine the exact depth of penetration due to refraction caused by the difference in refractive index between air and the polymer.

\section{Conclusions}

To sum up, we have demonstrated a novel strategy to inkjet print a broad range of polymeric materials with finely tuned mechanical, thermal and superficial properties. The synthesis of a modifiable material by post-polymerization, has made possible to adjust the mechanical properties of the films by subsequential solid phase reactions, namely quaternization, protonation and anion metathesis. The mechanical properties of the films showed a broad range of variation $\left(\Delta \mathrm{T}_{\mathrm{g}}=114.3^{\circ} \mathrm{C}\right)$ thus indicating the success of our synthetic strategy. The fine tuning of the formulations, allowed to inkjet print well-defined layers with a thickness of ca. $5 \mu \mathrm{m} /$ layer. In addition, successful post-printing functionalisation of the printed films (quaternization of the polyimidiazole, followed by subsequent anion metathesis) was demonstrated, highlighting the vast degree of exquisite control of the properties of 3D printed poly(ionic liquid) films that this technique makes possible. This work will pave the way for the development of devices with multiple compositions and complex printed geometries for a broad range of applications, including energy, sensing and catalysis.

\section{ACKNOWLEDGMENTS}

The University of Nottingham is gratefully acknowledged for a discipline bridge award and the Research Priority Areas for funding. EK gratefully acknowledges the Finnish Cultural Foundation (Suomen Kulttuurirahasto) for funding. D.J.W. and V.S. gratefully acknowledge the University of Nottingham Nanoscale and Microscale Research Centre (nmRC) for access to their instrumentation, in particular Dr. Graham A. Rance for confocal Raman microscopy analysis.

\section{SUPPORTING INFORMATION}

Experimental methods, videos, analytical data including NMR, IR, DSC, TGA, DMA and Raman spectra can be found in the supporting information. This material is available free of charge in the Supporting Information.

\section{Corresponding Author}

*e-mail: victor.sanssangorrin@nottingham.ac.uk ORCID: 0000-0001-7045-5244

\section{REFERENCES}

1. Derby, B., Inkjet Printing of Functional and Structural Materials: Fluid Property Requirements, Feature Stability, and Resolution. Annu. Rev. Mater. Res. 2010, 40 (1), 395-414. DOI: 10.1146/annurevmatsci-070909-104502

2 . Derby, B., Printing and Prototyping of Tissues and Scaffolds

Science 2012, 338 (6109), 921-926. DOI: 10.1126/science.1226340

3 . Kell, A. J.; Paquet, C.; Mozenson, O.; Djavani-Tabrizi, I.;

Deore, B.; Liu, X.; Lopinski, G. P.; James, R.; Hettak, K.; Shaker, J.;

Momciu, A.; Ferrigno, J.; Ferrand, O.; Hu, J. X.; Lafrenière, S.;

Malenfant, P. R. L., Versatile Molecular Silver Ink Platform for Printed

Flexible Electronics. ACS Appl. Mater. Interfaces 2017, 9 (20), 1722617237. DOI: 10.1021/acsami.7b02573

4. Kamyshny, A.; Magdassi, S., Conductive Nanomaterials for Printed Electronics. Small 2014, 10 (17), 3515-3535. DOI:

10.1002/smll.201303000.

5. Chi, K.; Zhang, Z. Y.; Xi, J. B.; Huang, Y. A.; Xiao, F.; Wang, S.; Liu, Y. Q., Freestanding Graphene Paper Supported Three-

Dimensional Porous Graphene-Polyaniline Nanoconnposite Synthesized

by Inkjet Printing and in Flexible All-Solid-State Supercapacitor. ACS

Appl. Mater. Interfaces 2014, 6 (18), 16312-16319. DOI: 10.1021/am504539k

6. Yamada, K.; Henares, T. G.; Suzuki, K.; Citterio, D., PaperBased Inkjet-Printed Microfluidic Analytical Devices. Angew. Chem. Int. Ed. 2015, 54 (18), 5294-5310. DOI: 10.1002/anie.201411508.

7. Angmo, D.; Larsen-Olsen, T. T.; Jorgensen, M.; Sondergaard, R. R.; Krebs, F. C., Roll-to-Roll Inkjet Printing and Photonic Sintering of Electrodes for ITO Free Polymer Solar Cell Modules and Facile Product Integration. Adv. Energy Mater. 2013, 3 (2), 172-175. DOI: 10.1002/aenm.201200520.

8. Gebler, M.; Schoot Uiterkamp, A. J. M.; Visser, C., A global sustainability perspective on 3D printing technologies. Energy Policy 2014, 74, 158-167. DOI: 10.1016/j.enpol.2014.08.033.

9. Welton, T., Room-temperature ionic liquids. Solvents for synthesis and catalysis. Chem. Rev. 1999, 99 (8), 2071-2083. DOI: $10.1021 / \mathrm{cr} 980032 \mathrm{t}$

10. Mecerreyes, D., Polymeric ionic liquids: Broadening the properties and applications of polyelectrolytes. Prog. Polym. Sci. 2011, 36 (12), 1629-1648. DOI: 10.1016/j.progpolymsci.2011.05.007

11. Yuan, J.; Mecerreyes, D.; Antonietti, M., Poly(ionic liquid)s: An update. Prog. Polym. Sci. 2013, 38 (7), 1009-1036. DOI:

10.1016/j.progpolymsci.2013.04.002

12. Qian, W.; Texter, J.; Yan, F., Frontiers in poly(ionic liquid)s: syntheses and applications. Chem. Soc. Rev. 2017, 46 (4), 1124-1159. DOI: 10.1039/C6CS00620E

13. Zhao, J.; Shen, X.; Yan, F.; Qiu, L.; Lee, S.; Sun, B., Solventfree ionic liquid/poly(ionic liquid) electrolytes for quasi-solid-state dyesensitized solar cells. J. Mater. Chem. 2011, 21 (20), 7326-7330. DOI:10.1039/C1JM10346F

14. Yan, F.; Yu, S.; Zhang, X.; Qiu, L.; Chu, F.; You, J.; Lu, J., Enhanced Proton Conduction in Polymer Electrolyte Membranes as Synthesized by Polymerization of Protic Ionic Liquid-Based Microemulsions. Chem. Mater. 2009, 21 (8), 1480-1484. DOI: $10.1021 / \mathrm{cm} 900098 \mathrm{r}$.

15. Ayalneh Tiruye, G.; Muñoz-Torrero, D.; Palma, J.; Anderson, M.; Marcilla, R., All-solid state supercapacitors operating at $3.5 \mathrm{~V}$ by using ionic liquid based polymer electrolytes. J. Power Sources 2015, 279, 472-480. DOI: 10.1016/j.jpowsour.2015.01.039

16. Burguete, M. I.; García-Verdugo, E.; Garcia-Villar, I.; Gelat, F.; Licence, P.; Luis, S. V.; Sans, V., Pd catalysts immobilized onto gelsupported ionic liquid-like phases (g-SILLPs): A remarkable effect of the nature of the support. J. Catal. 2010, 269 (1), 150-160. DOI: 10.1016/j.jcat.2009.11.002

17. Riduan, S. N.; Zhang, Y., Imidazolium salts and their polymeric materials for biological applications. Chem. Soc. Rev. 2013, 42 (23), 9055-9070. DOI: 10.1039/c3cs60169b

18. Montolio, S.; Vicent, C.; Aseyev, V.; Alfonso, I.; Burguete, M. I.; Tenhu, H.; García-Verdugo, E.; Luis, S. V., AuNP-Polymeric Ionic Liquid Composite Multicatalytic Nanoreactors for One-Pot Cascade Reactions. ACS Catal. 2016, 6 (10), 7230-7237. DOI:

10.1021/acscatal.6b01759 
19. Mao, H.; Zhang, H.; Liang, J.; Liu, D.; Wu, S.; Zhang, Y.; Zhang, Y.; Wu, Q.; Zhang, G.; Song, X.-M., Preparation of poly(ionic liquids)-functionalized polypyrrole nanotubes and their electrocatalytic application to simultaneously determine dopamine and ascorbic acid. $J$. Mater. Chem. B 2015, 3 (26), 5310-5317. DOI: 10.1039/C5TB00259A 20. Kim, T.; Lee, H.; Kim, J.; Suh, K. S., Synthesis of Phase Transferable Graphene Sheets Using Ionic Liquid Polymers. ACS Nano 2010, 4 (3), 1612-1618. DOI: 10.1021/nn901525e

21. Tokuda, M.; Thickett, S. C.; Minami, H.; Zetterlund, P. B., Preparation of Polymer Particles Containing Reduced Graphene Oxide Nanosheets Using Ionic Liquid Monomer. Macromolecules 2016, 49 (4), 1222-1228. DOI: 10.1021/acs.macromol.5b02216

22. Marcilla, R.; Alberto Blazquez, J.; Rodriguez, J.; Pomposo, J. A.; Mecerreyes, D., Tuning the solubility of polymerized ionic liquids by simple anion-exchange reactions. J. Poly. Sci. A 2004, 42 (1), 208-212. DOI: $10.1002 /$ pola.11015

23. Bhavsar, R. S.; Kumbharkar, S. C.; Rewar, A. S.; Kharul, U. K., Polybenzimidazole based film forming polymeric ionic liquids: synthesis and effects of cation-anion variation on their physical properties. Polym. Chem. 2014, 5 (13), 4083-4096. DOI:10.1039/C3PY01709E

24. Sans, V.; Karbass, N.; Burguete, M. I.; Compañ, V.; GarcíaVerdugo, E.; Luis, S. V.; Pawlak, M., Polymer-Supported Ionic-LiquidLike Phases (SILLPs): Transferring Ionic Liquid Properties to Polymeric Matrices. Chem. Eur. J. 2011, 17 (6), 1894-1906. DOI 10.1002/chem. 201001873

25. Schultz, A. R.; Lambert, P. M.; Chartrain, N. A.; Ruohoniemi, D. M.; Zhang, Z.; Jangu, C.; Zhang, M.; Williams, C. B.; Long, T. E., 3D Printing Phosphonium Ionic Liquid Networks with Mask Projection Microstereolithography. ACS Macro Lett. 2014, 3 (11), 1205-1209. DOI: $10.1021 / \mathrm{mz} 5006316$

26. Allen, M. H.; Hemp, S. T.; Smith, A. E.; Long, T. E., Controlled Radical Polymerization of 4-Vinylimidazole. Macromolecules 2012, 45 (9), 3669-3676. DOI: 10.1021/ma300543h.

27. Penzel, E.; Rieger, J.; Schneider, H. A., The glass transition temperature of random copolymers: 1 . Experimental data and the GordonTaylor equation. Polymer 1997, 38 (2), 325-337. DOI: 10.1016/S00323861(96)00521-6

28. Iwawaki, H.; Inoue, T.; Nakamura, Y., Rheo-Optical Study on Dynamics of Bottlebrush-Like Polymacromonomer Consisting of Polystyrene. Macromolecules 2011, 44 (13), 5414-5419. DOI: $10.1021 / \mathrm{ma} 2008332$
29. Nakamura, K.; Saiwaki, T.; Fukao, K.; Inoue, T., Viscoelastic Behavior of the Polymerized Ionic Liquid Poly(1-ethyl-3-

vinylimidazolium bis(trifluoromethanesulfonylimide)). Macromolecules 2011, 44 (19), 7719-7726. DOI: 10.1021/ma201611q

30. Choi, U. H.; Ye, Y.; Salas de la Cruz, D.; Liu, W.; Winey, K. I.; Elabd, Y. A.; Runt, J.; Colby, R. H., Dielectric and Viscoelastic Responses of Imidazolium-Based Ionomers with Different Counterions and Side Chain Lengths. Macromolecules 2014, 47 (2), 777-790. DOI: $10.1021 / \mathrm{ma} 402263 \mathrm{y}$

31. de Pedro, I.; Garcia-Saiz, A.; Dupont, J.; Migowski, P.;

Vallcorba, O.; Junquera, J.; Rius, J.; Fernandez, J. R., On the Colossal and Highly Anisotropic Thermal Expansion Exhibited by Imidazolium Salts. Cryst. Growth Des. 2015, 15 (11), 5207-5212. DOI:

10.1021/acs.cgd.5b00633

32. Williams, S. R.; Borgerding, E. M.; Layman, J. M.; Wang, W ; Winey, K. I.; Long, T. E., Synthesis and Characterization of Well-Defined 12,12-Ammonium Ionenes: Evaluating Mechanical Properties as a Function of Molecular Weight. Macromolecules 2008, 41 (14), 52165222. DOI: $10.1021 / \mathrm{ma} 802347 \mathrm{t}$

33. Hunley, M. T.; England, J. P.; Long, T. E., Influence of Counteranion on the Thermal and Solution Behavior of Poly(2(dimethylamino)ethyl methacrylate)-Based Polyelectrolytes. Macromolecules 2010, 43 (23), 9998-10005.

34. Godeau, G.; Navailles, L.; Nallet, F.; Lin, X.; McIntosh, T. J.; Grinstaff, M. W., From Brittle to Pliant Viscoelastic Materials with Solid State Linear Polyphosphonium-Carboxylate Assemblies. Macromolecules 2012, 45 (5), 2509-2513. DOI:10.1039/C5PY01631B

35. Ligon-Auer, S. C.; Schwentenwein, M.; Gorsche, C.; Stampfl, J.; Liska, R., Toughening of photo-curable polymer networks: a review. Polym. Chem. 2016, 7 (2), 257-286.

36. Stassen, H. K.; Ludwig, R.; Wulf, A.; Dupont, J., Imidazolium salt ion Pairs in solution. Chem. Eur. J. 2015, 21 (23), 8324-8335.

37. Wu, S.; Zhang, Q.; Chen, Z.; Mo, L.; Shao, S.; Cui, Z., J. Mater. Chem. C 2017, 5 (30), 7495-7503. DOI: 10.1039/C7TC01303E 38. Sans, V.; Gelat, F.; Burguete, M. I.; Garcia-Verdugo, E.; Luis, S. V., Polymer-supported Pd-NHC complexes: Strategies for the development of multifunctional systems. Catal. Today 2012, 196 (1), 137 147. DOI: $10.1016 /$ j.cattod.2012.03.036

Table of Contents/Abstract graphic

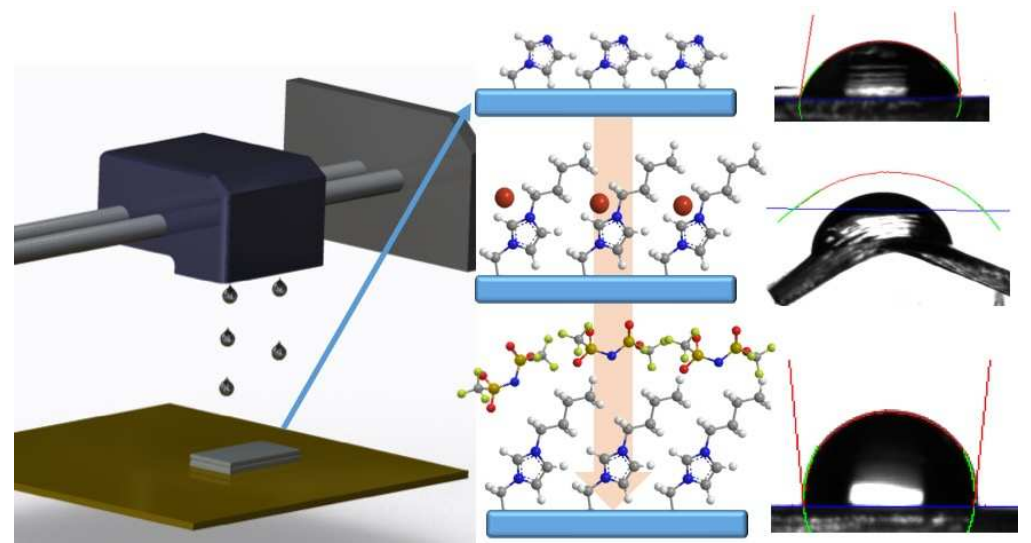

A new methodology is presented to successfully inkjet print polyionic liquids, avoiding the inherent viscosity limitations typically associated to ionic liquids. 